\title{
Identification of Putative Sources of Tolerance to Aphid in Mustard and Generation of Molecular Marker for Use in Crop Improvement
}

\author{
Subhash Chander ${ }^{1 *}$, Vikas C. Tyagi ${ }^{2}$, Deepali Sharma ${ }^{3}$, K. V. Bhat ${ }^{3}$ and Shashi Bhalla ${ }^{3}$ \\ ${ }^{1}$ ICAR-Directorate of Weed Research, Jabalpur, Madhya Pradesh 482004, India \\ ${ }^{2}$ ICAR-Indian Grassland and Fodder Research Institute, Jhansi, UP, India \\ ${ }^{3}$ National Bureau of Plant Genetic Resources, New Delhi 110 012, India \\ *Corresponding author
}

\begin{abstract}
A B S T R A C T
Keywords

Brassica juncea,

Lipaphiserysimi,

Polymorphism,

RAPD, SCAR

Article Info

Accepted:

22 May 2018

Available Online:

10 June 2018

RAPD (random amplified polymorphic DNA) analysis was used to identify molecular markers linked to putative gene conferring resistance to the mustard aphid (Lipaphis erysimi Kalt.). A set of 30 germplasm accessions of Brassica juncea were screened with 284 RAPD primers (87 primers were amplified) for analysis of putative source of aphid resistance. These amplified primers were screened with bulked DNA of tolerant and susceptible accessions and from that four polymorphic primers were obtained. These four primers were screened with individual tolerant and susceptible accessions and only one RAPD primer (oligos-193, Genemed 10-mer) with clear cut polymorphism between tolerant and susceptible accessions was obtained. This polymorphic band of $600 \mathrm{bp}$ found in susceptible was eluted from two accessions i.e. IC-491558 and IC-491564. DNA polymorphisms were converted in to SCAR (Sequence Characterized Amplified Region) primers (BJ 01 and BJ 02). These SCAR primers however could not provide unequivocal result since the association between marker and resistance was not always unidirectional. This indicates the need to further refine the marker identified by primer walking procedure.
\end{abstract}

\section{Introduction}

Indian mustard (Brassica juncea (L.) Czern.) has been an important crop to India for a long time. It is predominantly cultivated in Rajasthan, Uttar Pradesh, Haryana, Madhya Pradesh, and Gujarat (Shekhawatet al., 2012) and stands at the third position in the list of rape-mustard producing countries.However, India's average yield of mustard is low in comparison to other mustard-growing countries chiefly due to aphid pest causing excessive losses in the yield of the crop (Pandey et al. 2013; Rao et al. 2014).The yield loss in rapeseed mustard also varies with their germplasms and agro-ecological practices (Ansari, et al. 2007).The mustard aphid is considered to be a major limiting factor for successful cultivation of the crop; causing up to 96 per cent yield losses (Singh and Sachan, 1994; Singh and Premchand, 1995; Sharma and Kashyap, 1998; Singh and Sharma, 2002). Though, it can be controlled by the pesticide to some extent but it has 
residue left in the soil and oil products, which can cause adverse effect on the environment as well as human health; so, it is of utmost importance to mine for the sources of the genetic resistance against mustard aphid control mustard aphid using genetic resistance. Yadav et al., 2017 studied 240 B. juncea accessions for resistance/tolerance against mustard aphid and found 16 out of 240 accessions as resistant, 83 accessions falling under moderately resistant category, 102 accessions as susceptible accessions whereas 39 accessions were found to be highly susceptible. The percentage of highly resistant and tolerant germplasms in different species of Brassica ranged from $5 \%$ to $100 \%$ in closely related species (Jenson et al., 2002).

Plenty of research has been done in many field crops to explain the molecular mechanism behind the resistance to biotic stresses. A SCAR marker developed using RAPD molecular markers, linked to the Dn2 gene which confers resistance to the Russian wheat aphid (Diuraphis noxia Mordvilko) (Myburg et al., 1997). Monika et al., (2010) used Mi1.2 gene which when expressed in tomato plants, contributed to endogenous resistance against nematodes and some hemipteran insects. Similarly RAPD markers has been identified for white rust resistance in an $\mathrm{F}_{1-}$ derived doubled-haploid (DH) population originating from a cross between white rustsusceptible and white rust-resistant breeding lines of B. juncea (Prabhu et al., 1998). Molecular marker like RAPD and microsarellites has been efficiently utilized for tagging leaf rust resistance gene $\operatorname{Lr} 19$ in wheat (Gupta et al., 2006) and blackleg disease resistance gene analogues (RGA) in the B genome of Brassica (Saal et al., 2005). Atri et al., 2012 concluded that B. juncea - B. fruticulosa introgression set may prove to be a very powerful breeding tool for aphid resistance related QTL/gene discovery and fine mapping of the desired genes/QTLs to facilitate marker assisted transfer of identified gene(s) for mustard aphid resistance in the background of commercial mustard genotypes. With the above background and keeping in view of derth of information with regard to unavailability of SCAR marker in $B$. juncea against mustard aphid an attempt has been made to identify the putative source of aphid resistance employing DNA based molecular markers for the first time.

\section{Materials and Methods}

\section{Plant material}

A total of 34 accessions of B. juncea $(30$ accessions with 4 check) (Table-1) were grown at ICAR-NBPGR farm, New Delhi, during rabi 2009-10. The experiment was laid out in Randomized Block Design(RBD) with three replication. Tender and young leaf sample were collected for molecular studies.

\section{Scoring and screening of $B$. juncea accessions}

The screening was based on the parameters of Aphid Infestation Index (A.I.I.) and aphid population count. The aphid incidence appeared during mid of January and the observations were recorded at an interval of 15 days during the aphid period. The infestation was scored based on the 0-5 grades (Bakhetia and Sandhu, 1973) with slight modifications. The scale comprised (based on $0-5$ grades: highly tolerant $=0$ to 1 , tolerant $=$ 1.1 to 2 , moderately tolerant $=2.1$ to 3 , susceptible $=3.1$ to 4 , highly susceptible $=4.1$ to 5). The A.I.I. was calculated with the following formula

Aphid Infestation

Index

$=\frac{0 x a+1 x b+2 x c+3 x d+4 x e+5 x f}{a+b+c+d+e+f}$

Where $a, b, c, d, e$, and $f$ are the frequencies of plants falling in each grade from 0-5. 


\section{Aphid population}

For aphid population count was made at the initiation of inflorescence stage till the pod formation stage. For this purpose five randomly selected plants were tagged and top $10 \mathrm{~cm}$ apical twigs of the selected plants were cut and put in polythene bags separately and brought to the lab. The number of aphids per plant was counted under high magnification in the laboratory.

Based on mean aphid infestation index and aphid population, the accessions were grouped as highly tolerant, tolerant, moderately tolerant, susceptible and highly susceptible.

\section{Genomic DNA extraction}

Stored leaf samples of $B$. juncea was used for DNA extraction during 2010-11. DNA was extracted from leaf sample of individual plant the the CTAB extraction procedure of SaghaiMaroof et al., (1984), with minor modifications same as of Ruchi Vir et al., 2009. Extracted DNA was quantified using a Nanodrop spectrophotometer (ND1000 spectrophotometer, NanoDrop Technologies, Montchanin, DE) and diluted to $20 \mathrm{ng} / \mu \mathrm{l}$ in $1 \mathrm{x}$ T.E. The diluted samples were kept at $-20^{\circ} \mathrm{C}$ (Yamamoto et al., 1989).

\section{RAPD analysis}

Eighty seven RAPD primers (oligos-193, Genemed 10-mer) were selected based on good amplification, by using these primers 34 accessions of $B$. juncea were screened for analysis of putative source of aphid resistance. Two separate contrasting DNA bulks were made by pooling equal amount of DNA from susceptible and tolerant accessions and screened with above mentioned amplified RAPD primers.

PCR amplification was performed in a total volume of $25 \mu \mathrm{l}$ of Taq PCR buffer (10X),
dNTPs (20mM), $\mathrm{MgCl}_{2}(25 \mathrm{mM})$, Taq DNA polymerase $(5 \mathrm{U} / \mu \mathrm{l})$, (Fermentas, LIFE SCIENCE), with optimized conditions for PCR amplification was of an initial denaturation for 6 min at $94^{\circ} \mathrm{C}$, followed by 40 cycles each with denaturation for $1 \mathrm{~min}$ at $94^{\circ} \mathrm{C}$, annealing for $1 \mathrm{~min}$ at $35^{\circ} \mathrm{C}$ and extension for $1 \mathrm{~min}$ at $72^{\circ} \mathrm{C}$, with final extension of $10 \mathrm{~min}$ at $72^{\circ} \mathrm{C}$ and the reaction was carried in a Bioer XP cycler. Amplified PCR product was separated on $1.8 \%$ agarose gel, stained with Gelred (Life Technologies Pvt. Ltd, $5 \mu 1 / 100 \mathrm{ml})$. Gels were viewed and photographed under medium wavelength UV light. The amplification products were scored across the gel comparing their molecular weights.

\section{SCAR design and analysis}

Polymorphic fragments amplified by closely linked RAPD marker from two accessions (IC- 491558 and IC- 491564) were excised from the gel and purified using standard Gel elusion kit (Axygen biosciences, USA). The purified DNA was cloned into the pGEM-T Easy vector (Promega, Madison, WI, USA). The resulting white colonies on X-gal-IPTGLA plates containing $100 \mathrm{~g} / \mathrm{ml}$ ampicillin were picked, grown in Luria broth and plasmid DNA was isolated using the Sambrook and Russel (2001) method. Plasmid was then purified by treating with RNase A $(10 \mathrm{mg} / \mathrm{ml})$ followed by extraction with phenol chloroform. Isolated plasmid was run on $1 \%$ agarose gel, and the band size of blue and white colonies were compared, colonies containing band size larger than the control (blue colony) were considered as recombinant colonies (Fig. 3). The cloned fragment was sequenced from both ends using universal primers $\left(\mathrm{T}_{7}\right.$ and $\left.\mathrm{SP}_{6}\right)$ in automated DNA sequencer (Chromous Biotech, Bangalore, India). Based on the sequence information forward and reverse SCAR primers were designed using Oligos 4.0 software (National Biosciences) and were synthesized from 
Eurofins, Germany (Table 3). PCR amplification was performed in a total volume of $25 \mu \mathrm{l}$ of Taq PCR buffer (10X), dNTPs (20mM), $\quad \mathrm{MgCl}_{2} \quad(25 \mathrm{mM}), \quad$ Taq DNA polymerase $(5 \mathrm{U} / \mu \mathrm{l})$, (Fermentas, LIFE SCIENCE), SCAR primer $(1 \mu \mathrm{M})$ and template DNA $(20 \mathrm{ng} / \mu \mathrm{l})$. PCR amplifications programme consisted of an initial denaturation for $6 \mathrm{~min}$ at $94^{\circ} \mathrm{C}$, followed by 35 cycles each with denaturation for $1 \mathrm{~min}$ at $94^{\circ} \mathrm{C}$, annealing for $1 \mathrm{~min}$ at $54^{\circ} \mathrm{C}$ and extension for $1 \mathrm{~min}$ at $72^{\circ} \mathrm{C}$, with final extension of $10 \mathrm{~min}$ at $72^{\circ} \mathrm{C}$. Amplification products were separated on 1.5 agarose gel, stained with Gelred from Life Technologies Pvt. Ltd $(5 \mu 1 / 100 \mathrm{ml})$, visualised under UV light and photographed using gel documentation system (Syngene, Germany).

\section{Results and Discussion}

Thirty accessions were screened under condition of natural infestation of mustard aphid in the field conditions, in randomized block design with three replications each were screened for the resistance/tolerance to aphid. Eleven accessions were found to be under the tolerant category (with 9 being tolerant \& 2 highly tolerant), whereas 6 accessions were of susceptible category (three susceptible \& highly susceptible), remaining 13 accessions showed a reaction of moderately tolerance, when compared with tolerant and susceptible check.

The strain of $B$. juncea has tough inflorescence twigs with loosely packed flowers buds, which offer a less suitable site for colonization of aphid (Rai and Sehgal, 1975). Generally, B. juncea strains are also moderately resistant to $L$. erysimi infestation as compared to brown and yellow sarson (Singh et al., 1982; Rohilla et al., 1993; Bakhetia et al., 2002). The differential behaviour of germplasm/accessions ranged from highly susceptible to highly tolerant (Subhash et al., 2013).

Fig.1 Four RAPD Primers found Polymorphic with Separate Bulked DNA of Tolerant and Susceptible Accessions

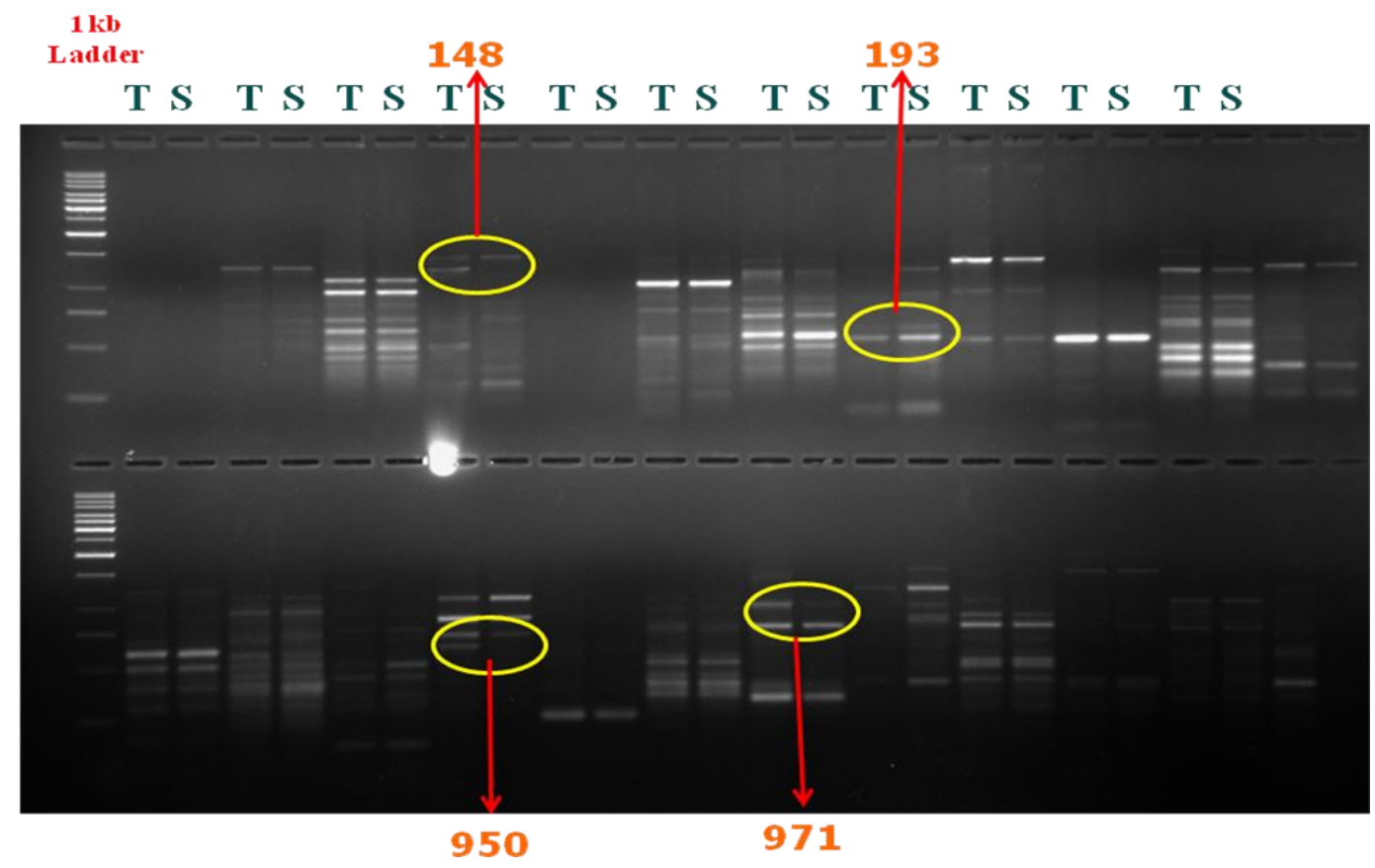


Fig.2 RAPD marker oligos-193 (Genemed 10-mer) shows an unique band of 600 bp in susceptible accessions which was absent in tolerant accessions

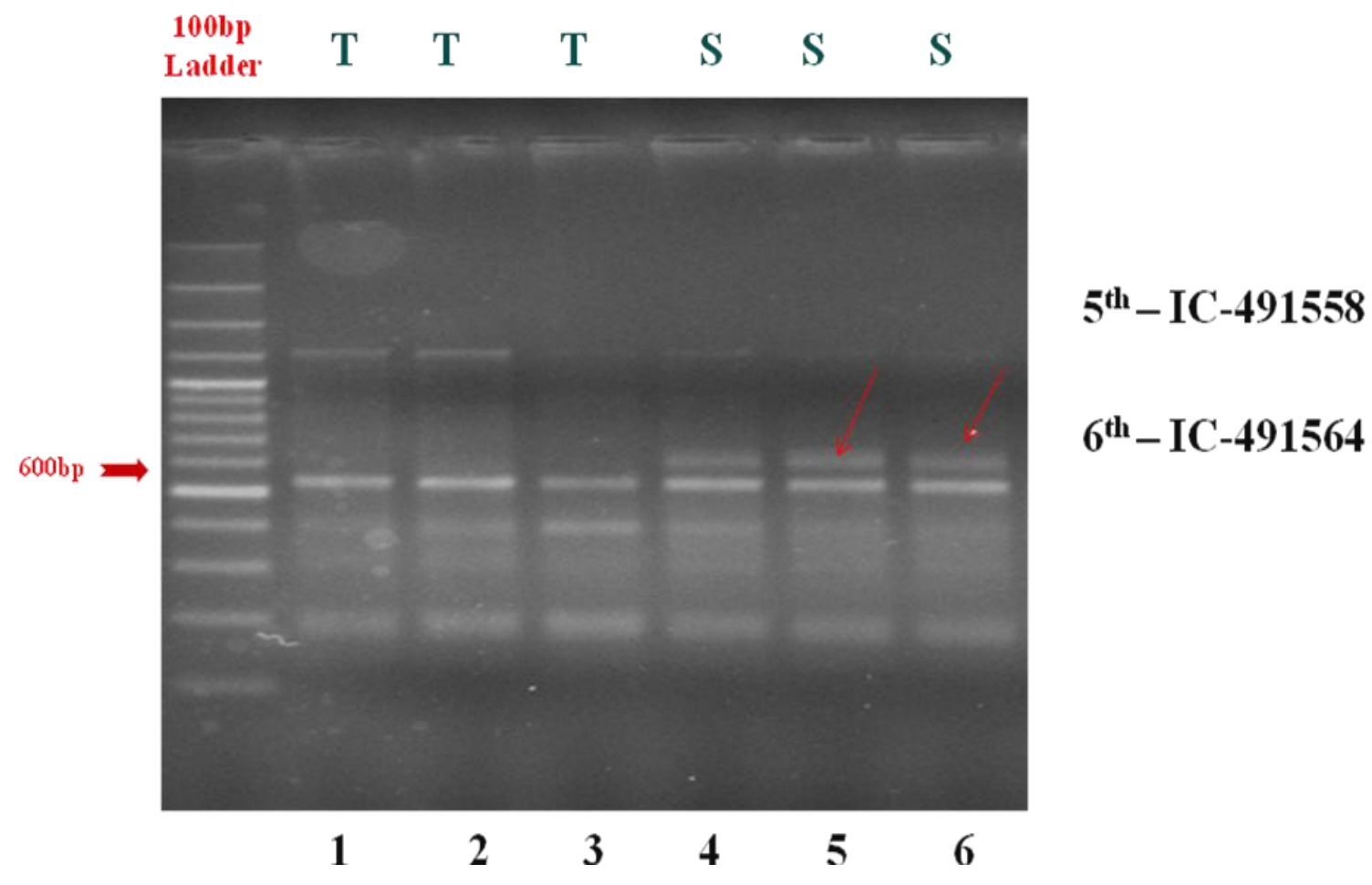

Fig.3 Confirmation of the transformed clones by comparing plasmid of blue and white colonies

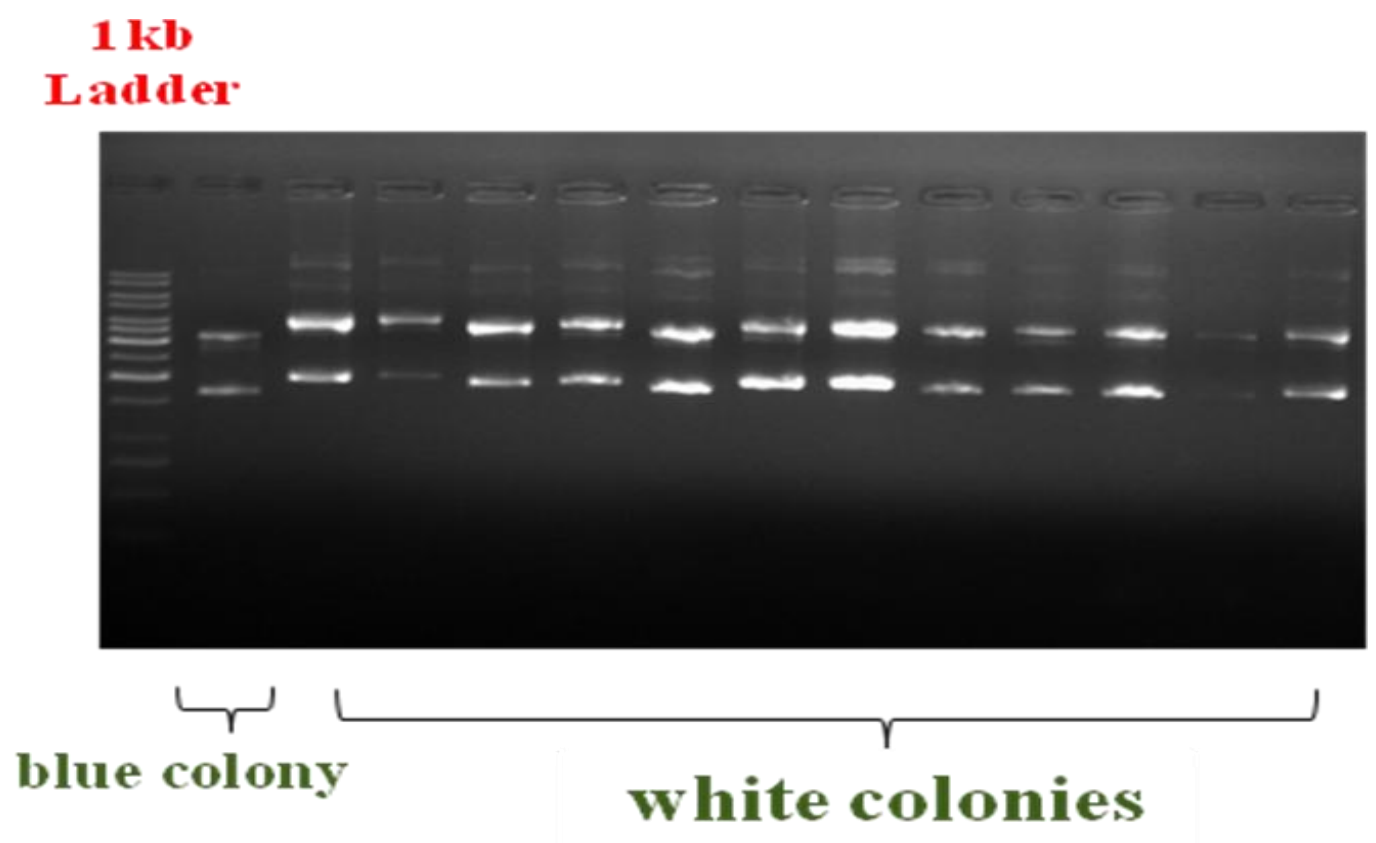


Table.1 Thirty four accessions of $B$. juncea with their reaction to mustard aphid under field conditions

\begin{tabular}{|c|c|c|}
\hline S.No & Accession & Reaction (A) \\
\hline C1 & PJ Kisan & $\mathrm{T}$ \\
\hline 1 & IC 326353 & HT \\
\hline 2 & IC 426349 & MT \\
\hline 3 & IC 491063 & MT \\
\hline 4 & IC 491260 & MT \\
\hline 5 & IC 491385 & MT \\
\hline 6 & IC 491386 & $\mathrm{~T}$ \\
\hline 7 & IC 491414 & HT \\
\hline 8 & IC 491416 & $\mathrm{~T}$ \\
\hline 9 & IC 491470 & MT \\
\hline 10 & IC 491472 & MT \\
\hline $\mathrm{C} 2$ & Rajat & MT \\
\hline 11 & IC 491473 & $\mathrm{~T}$ \\
\hline 12 & IC 491482 & MT \\
\hline 13 & IC 491488 & $\mathrm{~T}$ \\
\hline 14 & IC 491490 & S \\
\hline 15 & IC 491512 & $\mathrm{~T}$ \\
\hline 16 & IC 491515 & MT \\
\hline 17 & IC 491517 & MT \\
\hline 18 & IC 491521 & $\mathrm{~T}$ \\
\hline 19 & IC 491534 & $\mathrm{~T}$ \\
\hline 20 & IC 491541 & MT \\
\hline $\mathrm{C} 3$ & RH 30 & HS \\
\hline 21 & IC 491542 & $\mathrm{~T}$ \\
\hline 22 & IC 491543 & HS \\
\hline 23 & IC 491548 & MT \\
\hline 24 & IC 491554 & MT \\
\hline 25 & IC 491557 & $\mathrm{~T}$ \\
\hline 26 & IC 491558 & HS \\
\hline 27 & IC 491562 & MT \\
\hline 28 & IC 491564 & S \\
\hline 29 & IC 491565 & MT \\
\hline 30 & IC 491566 & $\mathrm{~S}$ \\
\hline C4 & Varuna & HS \\
\hline
\end{tabular}

A: Reaction of B. juncea accession to aphid based on visual observation; HS: Highly Susceptible, S: Susceptible, MT: Moderately Tolerant, T: Tolerant, HT: Highly Tolerant 
Fig.4 Amplification of SCAR marker with Tolerant and Susceptible accessions

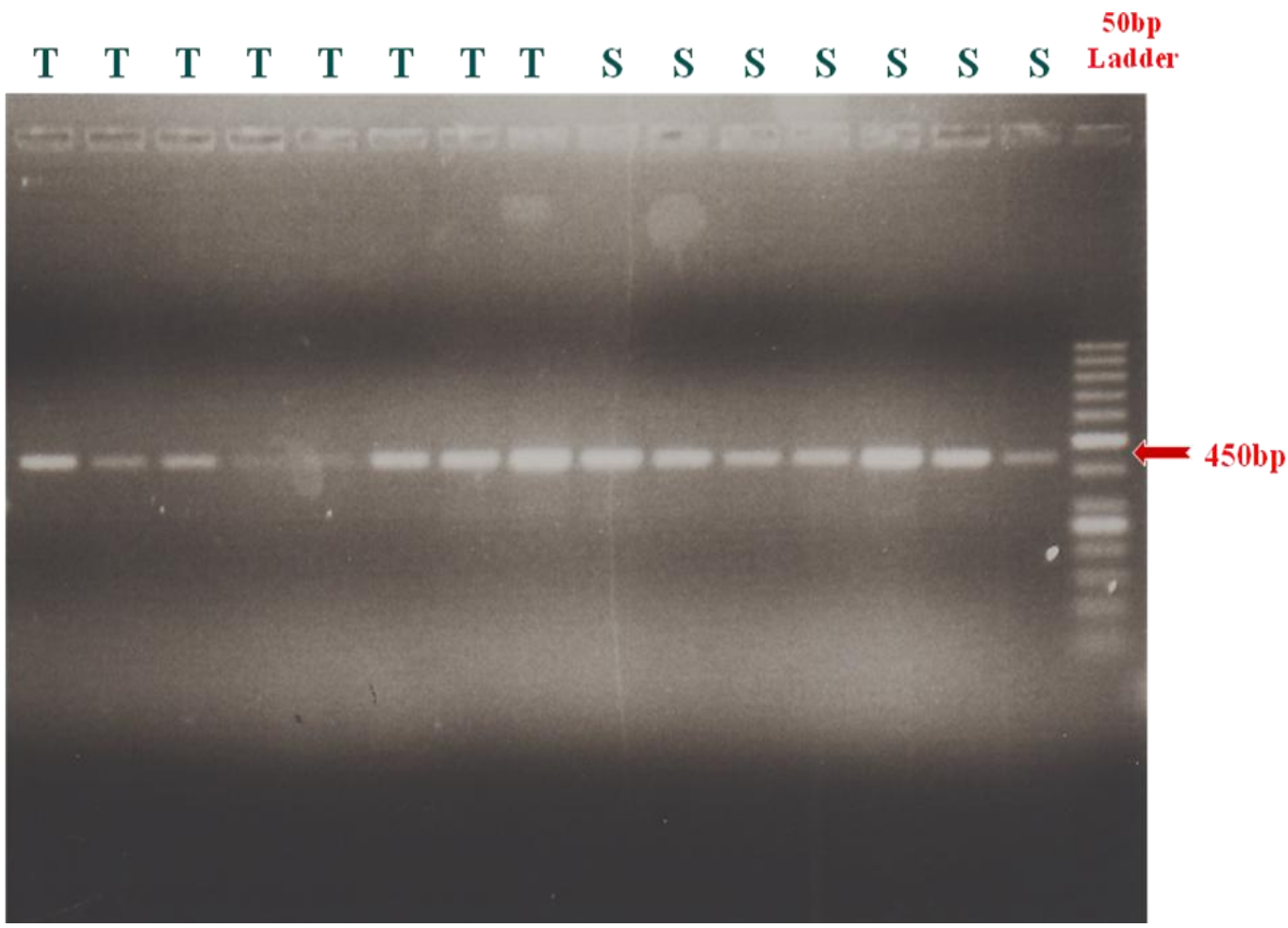

Table.2 GENEMED’S 10- MER Oligos Concentration 0.5 OD (16.5 $\mu \mathrm{g})$

\begin{tabular}{|c|c|c|}
\hline S. No. & Oligos NO & Sequences \\
\hline $\mathbf{1}$ & 148 & AGAGAGACAG \\
\hline $\mathbf{2}$ & 193 & CTATAGGCAG \\
\hline $\mathbf{3}$ & 950 & CCAGCCTCAT \\
\hline $\mathbf{4}$ & 971 & AGGCTGACTT \\
\hline
\end{tabular}

Table.3 SCAR primer sequences

\begin{tabular}{|l|l|c|c|}
\hline \multicolumn{1}{|c|}{ Primer ID } & \multicolumn{1}{|c|}{ Primer Sequence } & $\begin{array}{c}\text { Annealing } \\
\text { Temperature }\end{array}$ & $\begin{array}{c}\text { Amplicon } \\
\text { size (bp) }\end{array}$ \\
\hline BJ01 & $\begin{array}{l}\text { F: 5'-TATAGGCTATTTACTCCTGGG } \\
\text { R:5'-ATCACCTGGGAACTTGTCCC }\end{array}$ & 54.6 & 396 \\
\hline BJ102 & $\begin{array}{l}\text { F:5'-TGAGCGATAAAGGACATGGG } \\
\text { R:5'-GAGTTAAGCAGTAACGGGAGG }\end{array}$ & 52.2 & 445 \\
\hline
\end{tabular}




\section{Scoring and screening of $\boldsymbol{B}$. juncea accessions}

$\begin{array}{lll}\text { Scale } & \text { Aphid reaction } & \text { Aphid populations } \\ \text { 0.1-1.0 } & \text { Highly tolerant } & \leq 20 \text { mean no .of aphids } / 10 \mathrm{~cm} \text { inflorescence } \\ \text { 1.1-2.0 } & \text { Tolerant } & 20-50 \text { mean no .of aphids } / 10 \mathrm{~cm} \text { inflorescence } \\ \text { 2.1-3.0 } & \text { Moderately tolerant } & 51-100 \text { mean no .of aphids } / 10 \mathrm{~cm} \text { inflorescence } \\ 3.1-4.0 & \text { Susceptible } & 101-150 \text { mean no } . o f \text { aphids } / 10 \mathrm{~cm} \text { inflorescence } \\ \text { 4.1-5.0 } & \text { Highly susceptible } & >150 \text { mean no .of aphids } / 10 \mathrm{~cm} \text { inflorescence }\end{array}$

Genomic DNA from 11 tolerant accessions (referred to as tolerant/resistant bulk) and 6 susceptible accessions (referred to as susceptible bulk) were pooled separately. A total of 284 RAPD primers were used to screen the DNA of 4 accessions ( 2 tolerant and 2 susceptible) to find out the possible rate of amplification. The 87 primers showed quality amplification and were selected for further screening of tolerant and susceptible bulks. Amongst them only 4 RAPD primers showed polymorphism on tolerant and susceptible bulks. The results formed the basis to hypothesize the concept of putative sources of resistance backed by polymorphic RAPD markers. Further 4 polymorphic markers thus obtained were subjected to screen three randomly selected individual tolerant and susceptible accessions. Interestingly only single primer (oligos-193, CTATAGGCAG) showed clear cut polymorphism among the two contrasts. Specific locus was present in susceptible accessions (amplifying a band of $600 \mathrm{bp}$ ) and absent in the tolerant accessions.

This locus was isolated, cloned and sequenced; RAPD marker oligos-193 (Genemed 10-mer) was converted in to SCAR markers BJ-01and BJ-02. The locus specific markers for single band amplification are expected to provide ease of selection and reproducibility across laboratories. In the above study, the SCAR markers were ambiguous for distinguishing the tolerant and susceptible accessions as these primers gave similar band size of 450 bp with both the tolerant and susceptible accessions (Fig.4). Failure of SCAR markers to produce polymorphism either due to original RAPD polymorphisms was caused by mismatches in nucleotides in the priming sites as reported by Paran and Michelmore (1993) or due to the crossing over between the gene controlling the trait and marker.

Sufficient variation for tolerant and susceptible accessions were found in replicated trial, corresponding variation was also found at DNA level with RAPD analysis, but results could not validate with designed SCAR marker successfully, due to crossing over between the gene and marker or mismatches in nucleotides in the priming sites. Further study can be conducted to develop cleaved amplified polymorphic sequence (CAPS) by restriction digestion using RFLP analysis and fine mapping of this particular locus by developing mapping populations or genome walking technique. If 
we could tag this susceptible gene in $B$. juncea accessions, it would be very useful to find resistant sources using marker assisted selections (MAS).

\section{References}

Ansari, M.S., B. Hussain and Qazi, N.A. 2007. Influence of abiotic environment on the population dynamics of mustard aphid, Lipaphiserysimi (Kalt.) on Brassica Germplasm. J. Boil. Sci. 7: 993- 996.

Atri, C., B. Kumar, H. Kumar, S. Kumar, S. Sharma and Banga S.S. 2012. Development and characterization of Brassica juncea

fruticulosaintrogression lines exhibiting resistance to mustard aphid (LipaphiserysimiKalt). BMC genetics 13: 104.

Bakhetia, D. R. C., and Sandhu, R.S. 1973. Differential response of Brassica species/ varieties to the aphid, Lipaphiserysimi(kalt.) infestation. Journal of research, Punjab Agricultural University10(3): 272-279.

Bakhetia, D.R.C., H. Singh, and Chander, H. 2002. IPM for sustainable production of oilseeds. In: Oilseeds and Oils: Research and Development Needs, Indian Society of Oilseeds Research, (Rai, Mangala, Singh, Harvir and Hegde, D.M. (eds), Hyderabad, India pp, 184- 218.

Gupta, S.K., A. Charpe, K.V. Prabhu and Haque, Q. M. 2006. Identification and validation of molecular markers linked to the leaf rust resistance gene Lr19 in wheat. TheorAppl Genet 113: 10271036.

Jenson, E.B., G. Felkl, K. Kristiansen and Andersen S.B. 2002. Resistance to the cabbage root fly, Delia radicum within Brassica fruticulosa.Euphytica 124: 379-386.
Monika, G., S. Mirosława and Małgorzata, K. 2010. Relevance of the MI-23 marker and the potato aphid biology as indicators of tomato plant (Solanum lycopersicum) resistance to some pests. Vegetable Crops Research Bulletin72: 25-33

Myburg, A.A., M. Cawood, B.D. Wingfield and Botha, A. M. 1997. Development of RAPD and SCAR markers linked to the Russian wheat aphid resistance gene Dn2 in wheat. Theoretical and Applied Genetics96: 1162-1169.

Pandey, R., B. Kumar, Kumar, M. 2013. Genetic divergence for quantitative traits in Indian Mustard (Brassica juncea L. Czern\&Coss). Am Eurasian J Agric Environ Sci. 13(3):348-351.

Paran, I., and Michelmore, R.W. 1993. Development of reliable PCR based markers linked to downey mildew resistance genes in lettuce. Theoretical and Applied Genetics85: 985-993.

Prabhu, K.V., D.J. Somers, G. Rakow and Gugel, R.K. 1998. Molecular markers linked to white rust resistance in mustard Brassica juncea. Theoretical and Applied Genetics97: 865-870.

Rai, B., and Sehgal, V.K. 1975. Field resistance of Brassica germplasm to mustard aphid (Lipaphiserysimikalt.). Science and Culture41: 444-445.

Rao, B., V. Rao, L. Nair, Y. Prasad, A. Ramaragan, Chattopadhyay, C. 2014. Mustard aphid infestation in India Development of forewarning models. J Environ Biol. 35: 683-688.

Rohilla, H. R., H. Singh, Kumar, P. R. 1993. Strategies for the identification of the sources of resistance in oilseeds brassica against Lipaphiserysimi (Kalt.). Annals of Biomedical Engineering 9: 174-183.

Ruchi, V., K.V. Bhat and Lakhanpaul, S. 2009. Analysis of population substructure, genetic differentiation and 
phylogenetic relationships among selected Asiatic VignaSavi species. Genetic Resources and Crop Evolution 56:783-795.

Saal, B., and Struss, D. 2005. RGA- and RAPD-derived SCAR markers for a Brassica B-genome introgression conferring resistance to blackleg in oilseed rape. Theoretical and Applied Genetics111: 281-290.

Saghai-Maroof, M.A., K.M. Soliman, R.A. Jorgensen and R.W. Allard. 1984. Ribosomal DNA spacer-length polymorphisms in barley: Mendelian inheritance, chromosomal location, and population dynamics. Proc. Natl. Acad. Sci. (USA) 81:8014-8018.

Sharma, P.K. and Kashyap, N.P. 1998. Estimation of losses in three different oil seed Brassica crops due to aphid complex in Himachal Pradesh (India). Journal of Entomological Research 22: 22-25.

Shekhawat, K., S.S. Rathore, O.P. Premi, B.K. Kandpal, and Chauhan, J.S. 2012. Advances in Agronomic Management of Indian Mustard [Brassica juncea (L.) Czernj. Cosson]: An Overview. International Journal of Agronomy. doi:10.1155/2012/408284.

Singh, C.P. and Sachan, G.C. 1994. Assessment of yield losses in yellow sarson due to mustard aphid, Lipaphiserysimi (Kaltenbach). Journal of Oilseed Research 11: 179- 84.
Singh, P.K. and Premchand. 1995. Yield loss due to mustard aphid, Lipaphiserysimi $\mathrm{K}$. in Eastern Bihar Plateau. Journal of Applied Zoological Research 6: 97-100. Singh, R. N., R. Dass, G. Saran and Singh, K. K. 1982. Differential response of mustard varieties to Lipaphiserysimi (Kalt.). Indian journal of entomology44: 408.

Singh, Y.P. and Sharma, K.C. 2002. Integrated approach to manage the mustard aphid Lipaphiserysimi K. (Homotera: Aphididae) in oil seed Brassica crops-a review. Journal of Amphibiology 16: 77-88.

Subhash, C., T.V. Prasad, S. Ranbir, S. Subadas, R.D. Gautam and Shashi, B. 2013 Evaluation of Different Brassica Species against Mustard Aphid, Lipaphiserysimi. Indian J Plant Prot. 41(1): 38-44.

Yadav, U., R. K. Kantipudi and Mishra V. K. 2017. Screening of different varieties /accessions of mustard (Brassica juncea) against Lipaphiserysimi (kalt.) under natural conditions. Plant Archives 17 (1): 666-671.

Yamamoto, A., T. Araki, K. Fujimori, M. Yamada, H. Yamaguchi, K. Izumi and Matsumoto K. 1989. NaCl-aided Hoechst 33258 staining method for DNA quantification and its application. Histochemistry92(1): 65-80.

\section{How to cite this article:}

Subhash Chander, Vikas C. Tyagi, Deepali Sharma, K. V. Bhat and Shashi Bhalla. 2018. Identification of Putative Sources of Tolerance to Aphid in Mustard and Generation of Molecular Marker for Use in Crop Improvement. Int.J.Curr.Microbiol.App.Sci. 7(06): 30863095. doi: https://doi.org/10.20546/ijcmas.2018.706.363 